\title{
On the Regional Culture in the Novels of Gao Jianqun
}

\author{
Wang Baowei \\ Xi'an Aeronautical University, Xi'an, Shaanxi Province, 710077 \\ 184091867@qq.com
}

Key words: regional culture, Gao Jianqun, creation of novels, embodiment

\begin{abstract}
Since ancient times, literary creation of writers has been deeply influenced by times, natural environment and regional culture. Gao Jianqun is not an exception. He is writer with rich life experience, and his novels have a strong sense of regional culture. This paper aims to analyze mainly the embodiment of regional culture in novels of Gao Jianqun and the profound impact of which on his creation of novels.
\end{abstract}

\section{Introduction}

At all times and in all countries, literary creation of writers all has close connection with the environment in which they live and the local regional culture, which just unconsciously influences writers' creation. Their literary works are all about the description of the land where they live. Gao Jian qun is a typical example with a special life experience. He was born in the central part of Shaanxi province, but grew up in the northern part of Shaanxi province. In his adolescence, he once served as a cavalry for 5 years in Xin Jiang. The different regional culture of the three part of Shaanxi province has shaped Gao Jianqun’s unique aesthetic character.

\section{Aletai Grassland in Xin Jiang-Poetic Embodiment of Nomadic Culture}

Gao Jianqun's well-known work entitled The Remote White House which was written based on his unique military life in Xin Jiang and themed as frontier life. Gao Jianqun wrote the novel based on the White House which has become a special symbol of frontier station in Aletai grassland in Xin Jiang. Gao Jianqun continued his writing based on the White House for many years and many books were written, such as Yi Li Horse, Ma Deng Ge, Scowling Knight, The Origin of the Disputed Area of White House, etc.

The Remote White House mainly tells us a legendary story through the frontier guard "I". It's about the story happened in the frontier area between China and Russia, in which a crafty Russian invader wanted to aggressively occupy Chinese territory with tricks, but finally failed. The main male character Scissor Ma had a mysterious and legendary birth story. Scissor Ma was a bandit, later he became an officer who stationed on the border between China and Russia. He showed sympathy for the frontier soldiers in Russian border, so he lent them a piece of leather, which caused the border dispute and many people died. Finally, Scissor Ma blamed himself for this and chose to commit suicide. That is a tragic story. The main female character Sa Li Ha who is a very beautiful and amorous, chasing Scissor Ma till the very ending as a nun, which shows a mysterious and poetic quality in this novel. The writer's describes the historical events in the novel. Meanwhile, he also shows the poetic expression in a vast and rigorous fresh tactful tone.

According to Gao Jianqun's frontier novels, it can be found that they are all poetic, which mainly connects with his early experience of writing poems. We can see romance in him and this 
Romanism has been reflected in his writing of novels, which creates a poetic and romantic dash magnificent show. Scowling Knight tells us a story of frontier soldier "White House" through "I". "I" is a sentimental veteran, and the story focuses on the narration of "I" consciousness which hangs between "loess plateau" and "White House" back and forth. All these frontier novels have the same qualities. The story is unfolded along the "I" in the narration of the veteran, but "I" itself is a melancholy and fantasy person of romance. So "I" witnessed the authenticity of "the White House". Besides, it embodies a feature of mysterious, romantic and beautiful western nomadic culture.

In his frontier novels, Gao Jianqun put a strong sense of nomadic culture into them by creating some imageries about western nomadic culture. In The Remote White House, the writer created "the White House" to symbolize remoteness, loneliness and romance. He usually creates stories through telling the frontier culture. From The Remote White House, Gao Jianqun just began his writing based his military life, Plateau in Xin Jiang and the nomadic culture in "the White House" period. And he benefits a lot in his later writing about frontier-themed novels.

"In those novels, come with the fresh, lonely, desolate and magnificent and romantic western frontier culture.” Frontier imagery in Gao Jianqun's writings not only combine into symbols of rich culture and meaning life, but also embodies the nomadic culture in a poetic way.

\section{The Loess Plateau of Northern Part of Shaanxi-the Fusion of Nomadic Culture and Farming Culture}

The Loess Plateau in Northern Shaanxi Province is the intersection of farming culture and nomadic culture, which shows the characteristics of multi-national cultural integration, and has a unique regional culture. Gao Jianqun interpret the northern part of Shaanxi by regarding the regional culture as a key. In his eyes, not only has the unique natural characteristics of northern Shaanxi, but also the fusion of farming culture and nomadic culture, which has its unique historically and geographicallyregional culture. This kind of regional culture, embodied in many historical and cultural relics, in folk customs among (such as myths and legends, folk songs of Northern Shaanxi, paper-cut handicraft). It has penetrated into the bone and the soul of the people in northern Shaanxi, which shapes the character of the Northern Shaanxi and leads to rich and unique Shaanxi Cultural phenomenon.

Through the analysis of Gao Jianqun's novels about the Loess Plateau in northern Shaanxi Province, we can see theshadow of nomadic culture in the character of the people of Northern Shaanxi in Last Folk and Last Journey. In these two novels, Zhang Jia Shan is one of the most core characters, and the story is all based on his personal experience. In the dim years of Loess Plateau, Zhang Jia Shan was taken as the symbol of justice. Gao Jianqun was so affectionate to describe this character in this novel: "Zhang Jiashan's big face must have had something to do with Huns. It is known that the Huns in Northern Shaanxi were living on the land for a long time. His big and protruding nose has something to do with Dang Xiang people. Once a period, the Northern Shaanxi plateau was the home to Dang Xiang people who came fromQinghai. While after the perish in the Xi Xia Dynasty, it was believed that there were a lot of people back here.” [4] It can be seen that Zhang Jiashan was a bold, reckless, wild, generous, and the light of nomadic culture was exactly flashed in him.

Similarly, the people in the northern part of Shaanxi province are very bold, simple, strongandromantic, which is deeply influenced by the nomadic culture. Gao Jianqun was shocked at their qualities. So all the characters he portrayedhave the image of the nomadic blood, which is reflected in his creation of novels in the northern Shaanxi. For example, the ancestor of Yang's family in The Last Hanwas a Han soldier left behind. In Mother of the Veteran, that Old Liu who 
was good at playing the Suo $\mathrm{Na}$ (a kind of trumpet) was the descendant of Han people. While in Qi Lv Po Yi Gan Lv Han, the main character Li Jiyuan was the descendant of Li Zicheng. All the characters in Gao Jianqun's novels havetheir special identity. They are all the offspring of nomads, and they have different and great passion and unique life style. Therefore, a strong sense of nomadic culture has been flashed in their characters.

In Gao Jianqun's novels, he showed his amaze and compliment for the culture of Northern Shaanxi. He also knows that the farming culture of northern Shaanxi plays an important role in the development of the northern part of Shaanxi province. This magical land is an intersection of farming culture and nomadic culture, where people are deeply affected by these two cultures. They have the characteristics of pioneering spirit. Influenced by traditional farming culture, they also develop a habit of relocation of the land. Deeply attached to this land, their survival depends on the land and lived happily and harmoniously. They quietly stick in the bitter years, worked hard and toiled in millions of gullies on the land. They usually vent theirfeelings in the form of Xin Tian You. Sometimes they rest for a while and head up in the sky. However, they lived in this land for generations, they plant their dreams into the earth. Yang Ganda in The Last Han, had his greatest ideal of owinga circle of three junction Shi Yao, but he didn't make his dream come true. Liu Mengdie's life principle was to doing thing by turning tails. Their character and behaviors were deeply influenced and restricted by the farming culture.

In Gao Jianqun's masterpieceThe Last Xiong $\mathrm{Nu}$,, he put his writing in the grand cultural background of the Northern Shaanxi, and the folk stories, legends and folk songs interspersed among them. The author put the characters in the vast and profound environment to show. He showed a strong enthusiasm for the mottled cultural phenomenon of the Loess plateau. The mystery of the emergence and survival of the people in Northern Shaanxi are hidden in the natural landscape and the human landscape.

\section{Embodiment of the Profound Farming Culture in Wei He Plain of the Central Part of Shaaxi Province}

When Gao Jianqun put his writing from the perspective of the distant frontier to the plateau grassland of Northern Shaanxi, and published a series of works. We think grassland and plateauare the foundation of his writings, and these are the only source of his writing. It was not until the publication of The Great Plain that we realized that the Wei He Plain is also the source of his writing. Wei He Plain is the birthplace and the source of farming civilization, where the history of deep accumulation. Thousands of years of history and culture affect the people's character and psychology. It was once a strong and thriving area of feudal history and culture, but also the place with the most profound traditional culture. Gao Jianqun was born with sufferings, and his childhood was filled with hunger. He saw a lot of people die. Some of them starved to death or some were washed away by the flood, which has brought profound shock to his young mind, so that he has feelings of compassion. It makes him stubborn, sensitive and sad. He had a complex and deep feeling for the great plain where he had lived since childhood. Gao's family lived in this land for generations, and his history is also the microcosm of China's hundreds of years' history.

The small village,along the Wei River in The Great Plain, is a microcosm of China's tens of thousands of villages, and it is also a historical epitome of the suffering of the Chinese nation in the past century. From the three years of natural disasters to the Yellow River's breaking through its banks, from co-operatives to new period of reform and opening up, the rise of national urbanization, this small village bears the deep farming culture, but it can not ultimately be replaced by the fate of the change of city civilization. The Great Plain written by Gao Jianqun is not only a family history, 
but also a history of the development of rural life. Besides, it is also the history of the suffering of Chinese farmers in the past 100 years.

\section{Conclusion}

To conclude, Gao Jianqun's writings cannot do without Aletai Grassland in Xinjiang, the Loess Plateau of Northern Shaanxi, Wei He Plain of the Central of Shaanxi Province, and it has close connection with the special regional culture of the three areas. In his novels, the charm of regional culture has been reflected. These three kinds of different regional culture hav a profound impact on Gao Jianqun's novels, both showing the most real folk life, but also revealing the past, present and future of the Chinese nation.

\section{Acknowledgment}

Fund Project: Research Project Supported by Xi'an Aeronautical University, Study on the Creation of Novels from the Perspective of Regional Culture (2015KY2119); Research Project Supported by Education Department of Shaanxi Province, Study on the Regional Culture of Shaanxi Dialect based on Gao Jianqun’s Novels (16JK1391).

\section{References}

[1] Ruth Benedict. Wang Wei. Culture Mode [M]. Beijing: Joint Publishing, 1988(05)

[2] Li Feng. Talk to Gao Jianqun-I Take Every Piece of Work as the Last Will to Human Beings[J]. Jiang Nan, 2009(05)

[3]Liang Xiangyang. On Gao Jianqun's Frontier Novels-Poetic Writing of Legends[J]. Journal of Yi Li Normal University, 2004(06)

[4] Li Feng. Talk to Gao Jianqun-I Take Every Piece of Work as the Last Will to Human Beings[J]. Jiang Nan, 2009(05)

[5] Qian Mu. Chinese Civilization and Culture[J]. Discovery of Nature, 2001(05)

[6] Gao Jianqun. Grand Plateau[M]. Beijing: October Literature and Art Publishing House. 2009(02) 